\title{
Patient Satisfaction and Hand Performance Following Fingertip Reconstruction: A Retrospective Cohort Study
}

\author{
Daisuke Kaji, MD ${ }^{1}$ Shohei Omokawa, MD, PhD ${ }^{2}$ Akito Nakanishi, MD ${ }^{3}$ Kenji Kawamura, MD, PhD 4 \\ Takamasa Shimizu, MD, $\mathrm{PhD}^{4}$ Yasuhito Tanaka, MD, PhD ${ }^{4}$ \\ ${ }^{1}$ Limb Trauma Center, Nara City Hospital, Nara, Japan \\ ${ }^{2}$ Department of Hand Surgery, Nara Medical University, Nara, Japan \\ ${ }^{3}$ Department of Orthopedic Surgery, Takita Hospital, Nara, Japan \\ ${ }^{4}$ Department of Orthopedic Surgery, Nara Medical University, \\ Address for correspondence Shohei Omokawa, MD, PhD, \\ Department of Hand Surgery, Nara Medical University, \\ 840 Shijo-Cho, Kashihara, Nara 634-8522, Japan \\ (e-mail: omokawa@naramed-u.ac.jp).
}

Nara, Japan

J Reconstr Microsurg Open 2017;2:e78-e82.

Introduction Hand performance tests that evaluate hand dexterity and use in daily living have been frequently used to evaluate outcomes in patients with various hand disorders but not in patients with fingertip injuries. The present study aimed to evaluate patient satisfaction and hand performance following digital artery flap reconstruction for fingertip injury and identify factors associated with these outcomes. Methods This retrospective cohort study included 25 patients with amputation injuries at our institution between 2003 and 2013. Patients with amputations at the Tamai 1 or 2 zone of their index (14 patients) or middle finger (11 patients) who underwent digital artery flap surgery and were followed up for $>1$ year were included. Follow-up evaluations were conducted at an average of 44 months postoperatively (range, 12-105 months). The primary outcomes were patient satisfaction and hand performance determined by a 4-grade Likert scale and the Purdue Pegboard test, respectively. Secondary outcomes were recovery of sensitivity measured by SemmesWeinstein monofilaments, total active finger motion (TAM), and tip pinch strength. Results There were no postoperative complications. Patient satisfaction was rated as fair, good, and excellent, in 1, 15, and 9 patients, respectively. The average hand performance test scores were significantly lower in the affected finger than the adjacent finger ( $22 \mathrm{vs.} 30$, respectively; $p<0.05)$. The mean \pm standard deviation (SD) sensitivity test score was $3.5 \pm 1.6$ (range, 2.4-4.0). The average percentage TAM and tip pinch strength compared with the contralateral hand were 82 (range, 45-100\%) and 82\% (range, 60-112\%), respectively. The hand performance score significantly correlated with the recovery of sensitivity and age $(r=-0.42$ and 0.43 , respectively; both $p<0.05)$. Patient satisfaction was significantly correlated with TAM $(r=0.42, p<0.05)$ and tended to correlate with the recovery of sensitivity $(r=-0.395, p=0.051)$.

Conclusion Although reconstructed fingers had a lower performance score than the adjacent fingers, patient satisfaction with flap surgery was relatively high. Recovery of finger sensitivity contributed to patient satisfaction and enhanced dexterity of motor skill activities following fingertip reconstruction. received

December 31, 2016 accepted after revision May 25, 2017
DOI https://doi.org/

10.1055/s-0037-1604157. ISSN $2377-0813$.
Copyright $\odot 2017$ by Thieme Medical

Publishers, Inc., 333 Seventh Avenue, New York, NY 10001, USA Tel: +1(212) 584-4662.
License terms

(요 (1) $\Theta \circledast$ 
Outcomes assessed by physicians that include objective findings, such as recovery of sensibility, grip and pinch strength, and range of finger motion, have been used for evaluating hand function of patients with fingertip injury. Hand performance test ${ }^{1-5}$ is one of the important outcome measures for various hand disorders, which can evaluate dexterity of the hand and how patients actually use their hand in their daily living. There are several performance tests available for carpal tunnel syndrome, $^{2}$ Dupuytren's contracture, ${ }^{3}$ and rheumatoid hand. ${ }^{4}$ It is rather infrequent, however, to use hand performance test for evaluating fingertip injury. 5,6

In this study, we focused on evaluating patient satisfaction and hand performance following digital artery flap reconstruction for fingertip injury. We hypothesized that these outcomes would correlate with objective findings of recovery of sensitivity and range of finger motion. This study aimed to evaluate hand performance and patient satisfaction and identify factors influencing these outcomes following digital artery flap reconstruction for fingertip injury.

\section{Materials and Methods}

Between 2003 and 2013, 85 patients sustained amputation injury with an exposed bone at the level of Tamai zone 1 or 2 in their index and long fingers at our institution. When there was no bone exposure, secondary intention healing by occlusive dressing only was observed. Of these 85 patients, 35 underwent digital replantation or revision amputation. Fifty patients, who were not indicated for digital replantation and did not prefer revision amputation surgery, underwent digital artery flap surgery. Twenty-five patients with more than 1-year follow-up were enrolled in this study. This retrospective study had been conceived after 2013 and constructed from historical medical records back to 2003. We had gotten all 25 patients' cooperation after 2013 and the others had been excluded from this study because of inability to contact them. Power calculations to determine the detectable size of the correlation of outcomes based on the preliminary date of the current study indicated that a total sample size of 24 should provide $80 \%$ power for detecting significant correlation.

Fourteen patients sustained injury of index fingers and eleven of long fingers. The patients' average age was 48 (range: 22-72). There were 20 males and 5 female patients. Dominant hands were involved in 13 patients, and 12 were nondominant. Choice of the operation method was entrusted to each surgeon and surgical techniques had not been substantially changed over the 10 years of the study. Fourteen patients with volar oblique amputations underwent reverse-flow digital artery pedicle island flap, ${ }^{7} 9$ with transverse or lateral oblique amputations had oblique triangular advancement flap, ${ }^{8} 1$ with volar oblique amputation had neurovascular island flap, ${ }^{9}$ and 1 with transverse amputation had digital artery perforator flap. ${ }^{10}$ Oblique triangular advancement flap and neurovascular island flap were used as sensate flaps, and reverse-flow digital artery pedicle island flap and and digital artery perforator flap were used as insensate flaps in this series.
Donor site was closed primarily in patients with oblique triangular flap, and we used a split-thickness skin graft in cases with the other flaps. All patients began a hand therapy program at 1 week after surgery and exercised active assisted digital range of motion followed by passive finger motion and strengthening exercises. Sensory reeducation was started at the time of wound healing. Duration of these hand therapy programs averaged 3 months postoperatively. ${ }^{11}$ Follow-up evaluations of the current 25 patients were conducted with an average of 44 months (range: 12-105 months).

Primary outcome: We defined primary outcomes as patient satisfaction and hand performance status. Patients' satisfaction with esthetic and functional results was rated by four grades Likert scale of evaluation (excellent, good, fair, and poor). We used Purdue Pegboard test as a performance test. This test is a validated measure for evaluating hand function $^{2,12}$ and can quantify fine motor skill activities of the fingers. In this test, we scored the number of assemblies of pin and washers that were conducted in 1 minute. We measured scores in a situation using the affected finger followed by the adjacent finger.

Secondary outcome: Assessment of secondary outcomes included objective findings of recovery of sensitivity measured by Semmes-Weinstein monofilaments, ${ }^{13}$ total active finger motion (TAM), and strength of tip pinch. We also measured the strength of tip pinch and TAM of the contralateral hand, and percentage of these measures of the affected hand compared with those of the contralateral side was used for data analyses.

Statistical analysis: Correlations of the results of primary and secondary outcomes were analyzed by Spearman's correlation coefficient. Correlation of performance scores with age was analyzed as well. Scores of the hand performance test with and without using the affected finger were compared by Wilcoxon signed-rank test. Moreover, we evaluated the difference between sensate and insensate flap, and student's $t$-test was applied to compare the outcomes of the two groups. Values of $p$ less than 0.05 were considered statistically significant.

\section{Results}

There were no postoperative complications such as flap necrosis, surgical site infections, or complex regional pain syndrome. Patients' satisfaction with esthetic and functional results showed excellent, good, and fair scores in 9, 15, and 1 patients, respectively, following surgery. Hand performance scores using the affected finger averaged 22 , which was $56 \%$ of the normative population average. Scores using the adjacent finger averaged 30 , which was $77 \%$ of normative average. The performance test using the affected finger had a significantly lower score than that without using the affected finger $(p<0.05)$. As a secondary outcome of Semmes-Weinstein monofilaments test, 4 patients were green, 13 were blue, and 8 were purple, and the mean value of the test was 3.5 (standard deviation [SD]: 1.6, range: 2.4-4.0). Patients had averaged 82 (range: $45-100 \%$ ) of TAM and $82 \%$ (rang: $60-112 \%$ ) of tip pinch strength compared with the contralateral hand (-Table 1-3). 
Table 1 Patient information

\begin{tabular}{|c|c|c|c|c|c|c|c|c|c|}
\hline $\begin{array}{l}\text { No of cases, } \\
\text { gender }\end{array}$ & Age & Injured digit & $\begin{array}{l}\text { Direction of } \\
\text { amputation }\end{array}$ & Type of surgery & $\begin{array}{l}\text { PPT } \\
\text { score }\end{array}$ & $\begin{array}{l}\text { Patient } \\
\text { satisfaction }\end{array}$ & $\begin{array}{l}\text { TAM } \\
(\%)\end{array}$ & $\begin{array}{l}\text { Pinch } \\
(\%)\end{array}$ & $\begin{array}{l}\text { Sensitivity } \\
\text { scores }\end{array}$ \\
\hline 1 , female & 36 & Right index & Volar oblique & RDAF (insensate) & 31 & Good & 89 & 95 & 3.22 \\
\hline 2 , female & 38 & Right long & Volar oblique & RDAF (insensate) & 32 & Excellent & 95 & 100 & 3.22 \\
\hline 3, male & 51 & Left index & Volar oblique & RDAF (insensate) & 25 & Good & 62 & 72 & 3.61 \\
\hline 4 , female & 48 & Right long & Volar oblique & RDAF (insensate) & 33 & Excellent & 93 & 92 & 2.83 \\
\hline 5 , male & 37 & Right index & Volar oblique & RDAF (insensate) & 16 & Excellent & 86 & 83 & 2.44 \\
\hline 6 , male & 35 & Left index & Volar oblique & RDAF (insensate) & 45 & Excellent & 97 & 89 & 3.22 \\
\hline 7 , male & 49 & Right index & Volar oblique & RDAF (insensate) & 23 & Good & 87 & 62 & 3.84 \\
\hline 8 , female & 63 & Right index & Volar oblique & RDAF (insensate) & 24 & Excellent & 80 & 60 & 4.08 \\
\hline 9 , male & 63 & Right long & Volar oblique & RDAF (insensate) & 15 & Fair & 81 & 77 & 3.61 \\
\hline 10 , male & 72 & Left long & Volar oblique & RDAF (insensate) & 7 & Good & 83 & 76 & 3.84 \\
\hline 11 , male & 39 & Right index & Volar oblique & RDAF (insensate) & 11 & Good & 79 & 78 & 3.61 \\
\hline 12 , male & 23 & Left index & Volar oblique & RDAF (insensate) & 26 & Good & 73 & 73 & 3.61 \\
\hline 13 , male & 42 & Right index & Volar oblique & RDAF (insensate) & 23 & Excellent & 100 & 68 & 3.22 \\
\hline 14 , male & 57 & Left index & Volar oblique & RDAF (insensate) & 15 & Good & 45 & 67 & 3.84 \\
\hline 15 , male & 61 & Left long & Transverse & DAPF (insensate) & 14 & Good & 90 & 77 & 3.84 \\
\hline 16 , male & 35 & Right long & Transverse & OTF (sensate) & 17 & Good & 72 & 78 & 3.61 \\
\hline 17, male & 72 & Right index & Transverse & OTF (sensate) & 11 & Good & 65 & 89 & 3.61 \\
\hline 18 , male & 22 & Right long & Lateral oblique & OTF (sensate) & 25 & Excellent & 96 & 96 & 2.83 \\
\hline 19, male & 51 & Left long & Transverse & OTF (sensate) & 29 & Good & 94 & 100 & 2.44 \\
\hline 20 , male & 30 & Left long & Lateral oblique & OTF (sensate) & 25 & Excellent & 62 & 63 & 3.84 \\
\hline 21 , male & 70 & Left index & Lateral oblique & OTF (sensate) & 14 & Good & 74 & 89 & 4.08 \\
\hline 22, male & 62 & Right long & Transverse & OTF (sensate) & 25 & Good & 99 & 89 & 3.61 \\
\hline 23 , female & 67 & Right index & Transverse & OTF (sensate) & 21 & Excellent & 87 & 100 & 3.61 \\
\hline 24, male & 28 & Left long & Transverse & OTF (sensate) & 13 & Good & 91 & 75 & 3.61 \\
\hline 25 , male & 49 & Left index & Volar oblique & NVIF (sensate) & 28 & Good & 76 & 112 & 4.08 \\
\hline
\end{tabular}

Abbreviations: DAPF: digital artery perforator flap; NVIF: neurovascular island flap; pinch (\%), percentage of pinch strength measured in the affected hand compared with that of the contralateral side; OTF, oblique triangular advancement flap; PPT, Purdue Pegboard test (hand performance test); RDAF, reverse-flow digital artery pedicle island flap; TAM (\%), percentage of total active motion (TAM) of the affected finger compared with that of the contralateral side.

Table 2 Summary of characteristics, average \pm SD

\begin{tabular}{|c|c|c|}
\hline \multirow{2}{*}{$\begin{array}{l}\text { Patient } \\
\text { characteristics }\end{array}$} & Age (y) & $48 \pm 15(22-72)$ \\
\hline & Gender & Male: 20 \\
\hline \multirow{7}{*}{$\begin{array}{l}\text { Injury } \\
\text { characteristics }\end{array}$} & \multirow[t]{2}{*}{ Injured digit } & Index: 14 \\
\hline & & Long: 11 \\
\hline & \multirow[t]{2}{*}{ Hand dominance } & Dominant: 14 \\
\hline & & Nondominant: 11 \\
\hline & \multirow{3}{*}{$\begin{array}{l}\text { Direction of } \\
\text { amputation }\end{array}$} & Volar oblique: 15 \\
\hline & & Transverse: 7 \\
\hline & & Lateral oblique: 3 \\
\hline \multirow{2}{*}{$\begin{array}{l}\text { Surgical } \\
\text { characteristics }\end{array}$} & \multirow[t]{2}{*}{ Surgical procedure } & Insensate flap: 15 \\
\hline & & Sensate flap: 10 \\
\hline $\begin{array}{l}\text { Follow-up } \\
\text { period (mo) }\end{array}$ & & $44 \pm 15(12-105)$ \\
\hline
\end{tabular}

Abbreviation: SD, standard deviation.
Table 3 Summary of outcomes, average \pm SD

\begin{tabular}{|l|l|l|}
\hline $\begin{array}{l}\text { Primary } \\
\text { outcomes }\end{array}$ & $\begin{array}{l}\text { Performance } \\
\text { score }\end{array}$ & $\begin{array}{l}\text { Using adjacent finger: } \\
30 \pm 10(14-51)\end{array}$ \\
\cline { 2 - 3 } & & $\begin{array}{l}\text { Using affected finger: } \\
22 \pm 8.5(7-45)\end{array}$ \\
\cline { 2 - 3 } & $\begin{array}{l}\text { Patients' } \\
\text { satisfaction }\end{array}$ & $\begin{array}{l}\text { Excellent: 9, Good: } \\
\text { 15, Fair: 1 }\end{array}$ \\
\hline \multirow{2}{*}{$\begin{array}{l}\text { Secondary } \\
\text { outcomes }\end{array}$} & $\begin{array}{l}\text { S-W } \\
\text { monofilaments }\end{array}$ & $3.5 \pm 0.5(2.4-4.1)$ \\
\cline { 2 - 3 } & TAM (\%) & $82 \% \pm 13(45-100)$ \\
\cline { 2 - 3 } & $\begin{array}{l}\text { Tip pinch } \\
\text { strength (\%) }\end{array}$ & $82 \% \pm 13(60-112)$ \\
\hline
\end{tabular}

Abbreviations: TAM (\%), percentage of total active motion (TAM) of the affected finger compared with that of the contralateral side; SD, standard deviation; S-W, Semmes-Weinstein. 
Table 4 Correlation between primary and secondary outcomes

\begin{tabular}{|l|l|l|l|l|}
\hline & & S-W & TAM (\%) & Pinch (\%) \\
\hline \multirow{2}{*}{ PPT (with using) } & $r$ & -0.42 & $0.37^{2}$ & 0.37 \\
\cline { 2 - 5 } & $p$ & $0.04^{\mathrm{a}}$ & $0.07^{\mathrm{b}}$ & $0.07^{\mathrm{b}}$ \\
\hline Satisfaction & $r$ & -0.4 & 0.42 & 0.15 \\
\cline { 2 - 5 } & $p$ & $0.05^{\mathrm{b}}$ & $0.04^{\mathrm{a}}$ & 0.47 \\
\hline
\end{tabular}

Abbreviations: Pinch (\%), percentage of pinch strength measured in the affected hand compared with that of the contralateral side; TAM (\%), percentage of total active motion of the affected finger compared with that of the contralateral side; PPT, Purdue Pegboard test score using the injured finger; S-W, Semmes-Weinstein monofilaments test. ${ }^{a} p<0.05$,

$\mathrm{b}_{p}<0.1$.

Regarding correlations of the performance score with the secondary outcome measures, the score with the use of affected finger correlated significantly with the recovery of sensitivity $(r=-0.42, p<0.05)$. The score had a trend to correlate with the strength of tip pinch $(p=0.07)$ and TAM $(p=0.07)$. Patient satisfaction score significantly correlated with TAM $(r=0.42, p<0.05)$ and had a trend to correlate with the recovery of sensitivity $(r=-0.40, p=0.05)$. There was a significant correlation between hand performance scores and age $(r=0.43, p<0.05$, - Table 4$)$.

Pinch strength following sensate flap transfer was better than that with insensate flap $(p<0.05)$. There were no significant differences regarding the results of performance test, satisfaction, sensory recovery, or TAM between the patients with sensate and insensate flaps (-Table 5).

\section{Discussion}

Twenty-four of the 25 patients (96\%) in the present series rated the overall satisfaction with flap surgery as excellent and good. Although fingertip replantation provides excellent cosmetic outcome by maintaining the digital length, ${ }^{14}$ most of the current patients were satisfied with aesthetic and functional results following fingertip reconstruction by flap surgery. Digital flap surgery provided feasible patients' satisfaction for fingertip amputation injuries when there was no postoperative complication with minimum donor-site morbidity.

Although the current flap surgery showed a high patient satisfaction, finger dexterity test scores were relatively lower than normative population average. When the patients used an affected finger in the dexterity test, the average score (56\% of normative values) was significantly lower than that (77\%) with the adjacent finger. This result indicates that the digital flap surgery does not restore complete fine motor skill activities of the injured finger even if high postoperative hand therapy program was achieved. Decrease of sensitivity and daily usage of affected finger may have contributed to intrinsic muscle weakness and stiffness of finger joints, leading to reduction of dexterity of the injured finger.

The ultimate goal of fingertip injury is to restore stable and sensate pulp with aesthetically pleasing nail. Finger mobility, pinch power, and sensation of the finger may influence hand dexterity following fingertip reconstruction. 6,15 The current result of significant correlation of finger sensitivity with performance scores and a trend of correlation with patient satisfaction indicated that recovery of sensibility was an important determinant for the primary outcomes. Usami et $\mathrm{al}^{16}$ retrospectively compared sensory recovery in reverse digital artery island flaps and oblique triangular advancement flaps. They reported that two-point discrimination tests with a reverse digital artery island flap required a longer period for sensory recovery compared with an oblique triangular advancement flap. Yan et $\mathrm{al}^{17}$ reported a comparative study of finger pulp reconstruction using arterialized venous sensate flap and insensate flap from the forearm. They observed that the loss of pinch strength in the insensate flap group was larger than that in the sensate flap group. In this study, despite the absence of a significant difference in sensibility and hand performance between the sensate and insensate flap groups, longer durations until sensory recovery might have influenced the weakness of pinch strength in patients with insensate flap transfer. Thus, we consider that surgeons should choose sensory flap for fingertip reconstruction.

Age is another determinant of decreased hand performance. The relationship between increased age and reduced hand dexterity has been widely reported in the clinical literature. Martin et al ${ }^{18}$ examined the association between age, grip strength, and dexterity using 109 healthy adult participants and analyzed multiple regression models to determine which of the age and strength factors accounted for the greater variance in dexterity. Their analyses showed that age and strength significantly moderated hand dexterity, with the two variables explaining between 35 and $46 \%$ of the different hand dexterity tasks variance. The possibly notable age-related

Table 5 Comparison of outcomes between insensate and sensate flaps

\begin{tabular}{|l|l|l|l|l|l|l|}
\hline & Age & PPT score & Satisfaction & TAM (\%) & Pinch (\%) & Sensitivity scores \\
\hline Insensate flap & $48 \pm 13$ & $23 \pm 9$ & $3 \pm 0.6$ & $83 \pm 14$ & $78 \pm 11$ & $3.5 \pm 0.4$ \\
\hline Sensate flap & $49 \pm 18$ & $21 \pm 6$ & $3 \pm 0.4$ & $82 \pm 13$ & $89 \pm 13$ & $3.5 \pm 0.5$ \\
\hline$p$-Values & 0.9 & 0.6 & 0.7 & 0.8 & $0.04^{\mathrm{a}}$ & 0.7 \\
\hline
\end{tabular}

Abbreviations: Pinch (\%), percentage of pinch strength measured in the affected hand compared with that of the contralateral side; PPT score, scores of Purdue Pegboard test; TAM (\%), percentage of total active motion (TAM) of the affected finger compared with that of the contralateral side. Notes: Each value indicates average \pm standard deviation.

Patients' satisfaction was scored by four grades Likert scale of evaluation (excellent: 4, good: 3, fair: 2, and poor: 1).

${ }^{a} p<0.05$. 
changes in muscle properties are a slowed rate of muscle contraction, ${ }^{19,20}$ a slowed neural conduction velocity, ${ }^{21,22}$ and an increased muscle antagonist coactivation that is necessary to stabilize a joint during a movement. ${ }^{23}$ Preexisting joint arthrosis, muscle weakness, and lower neuromuscular controls in elderly patients may adversely affect hand dexterity, and the more prolonged rehabilitation protocols may improve postoperative outcomes.

The limitations of this study are that it included small case samples and was a retrospective study. Accumulating prospective cohort to investigate independent factors influencing the hand performance by multivariate analysis are warranted.

\section{Conclusion}

Despite the lower value of performance score in the reconstructed finger compared with the adjacent finger, patient satisfaction with flap surgery was relatively high. Recovery of finger sensitivity contributed to patient satisfaction and enhanced dexterity of motor skill activities following fingertip reconstruction.

\section{References}

1 Sears ED, Chung KC. Validity and responsiveness of the JebsenTaylor hand function test. J Hand Surg Am 2010;35(01):30-37

2 Amirjani N, Ashworth NL, Olson JL, Morhart M, Chan KM. Validity and reliability of the Purdue Pegboard test in carpal tunnel syndrome. Muscle Nerve 2011;43(02):171-177

3 Draviaraj KP, Chakrabarti I. Functional outcome after surgery for Dupuytren's contracture: a prospective study. J Hand Surg Am 2004;29(05):804-808

4 Bogoch ER, Escott BG, Ronald K. Hand appearance as a patient motivation for surgery and a determinant of satisfaction with metacarpophalangeal joint arthroplasty for rheumatoid arthritis. J Hand Surg Am 2011;36(06):1007-1014.e1-4

5 Kotkansalo T, Vilkki SK, Elo P. The functional results of posttraumatic metacarpal hand reconstruction with microvascular toe transfers. J Hand Surg Eur Vol 2009;34(06):730-742

6 Chen HY, Hsu CC, Lin YT, Yeh JT, Lin CH, Lin CH. Functional and aesthetic outcomes of the fingertips after nail lengthening using the eponychial flap. J Plast Reconstr Aesthet Surg 2015;68(10): 1438-1446

7 Kojima T, Tsuchida Y, Hirasé Y, Endo T. Reverse vascular pedicle digital island flap. Br J Plast Surg 1990;43(03):290-295
8 Venkataswami R, Subramanian N. Oblique triangular flap: a new method of repair for oblique amputations of the fingertip and thumb. Plast Reconstr Surg 1980;66(02):296-300

9 Littler JW. The neurovascular pedicle method of digital transposition for reconstruction of the thumb. Plast Reconstr Surg (1946) 1953;12(05):303-319

10 Koshima I, Urushibara K, Fukuda N, et al. Digital artery perforator flaps for fingertip reconstructions. Plast Reconstr Surg 2006; 118(07):1579-1584

11 Giladi AM, McGlinn EP, Shauver MJ, Voice TP, Chung KC. Measuring outcomes and determining long-term disability after revision amputation for treatment of traumatic finger and thumb amputation injuries. Plast Reconstr Surg 2014;134(05):746e-755e

12 Shahar RB, Kizony R, Nota A. Validity of the Purdue Pegboard test in assessing patients after traumatic hand injury. Work 1998; 11(03):315-320

13 Jerosch-Herold C. Assessment of sensibility after nerve injury and repair: a systematic review of evidence for validity, reliability and responsiveness of tests. J Hand Surg Br 2005;30(03):252-264

14 Jazayeri L, Klausner JQ, Chang J. Distal digital replantation. Plast Reconstr Surg 2013;132(05):1207-1217

15 Walaszek I, Zyluk A. Long term follow-up after finger replantation. J Hand Surg Eur Vol 2008;33(01):59-64

16 Usami S, Kawahara S, Yamaguchi Y, Hirase T. Homodigital artery flap reconstruction for fingertip amputation: a comparative study of the oblique triangular neurovascular advancement flap and the reverse digital artery island flap. J Hand Surg Eur Vol 2015;40(03): 291-297

17 Yan H, Gao W, Zhang F, Li Z, Chen X, Fan C. A comparative study of finger pulp reconstruction using arterialised venous sensate flap and insensate flap from forearm. J Plast Reconstr Aesthet Surg 2012;65(09):1220-1226

18 Martin JA, Ramsay J, Hughes C, Peters DM, Edwards MG. Age and grip strength predict hand dexterity in adults. PLoS One 2015; 10(02): 0117598

19 Doherty TJ, Brown WF. Age-related changes in the twitch contractile properties of human thenar motor units. J Appl Physiol (1985) 1997;82(01):93-101

20 Doherty TJ, Vandervoort AA, Taylor AW, Brown WF. Effects of motor unit losses on strength in older men and women. J Appl Physiol (1985) 1993;74(02):868-874

21 Bouche P, Cattelin F, Saint-Jean O, et al. Clinical and electrophysiological study of the peripheral nervous system in the elderly. J Neurol 1993;240(05):263-268

22 Norris AH, Shock NW, Wagman IH. Age changes in the maximum conduction velocity of motor fibers of human ulnar nerves. J Appl Physiol 1953;5(10):589-593

23 Carmeli E, Patish H, Coleman R. The aging hand. J Gerontol A Biol Sci Med Sci 2003;58(02):146-152 